\title{
Organisational factors in the implementation of educational modules at schools in Barranquilla (Colombia)
}

Isidro Maya-Jariego (1] ${ }^{1 凶}$, Andrés Muñoz-Alvis², Jean David Polo-Vargas², Jorge E. Palacio-Sañudo (i) ${ }^{2} \&$ Alberto M. de Castro-Correa ${ }^{2}$

Job design affects motivational aspects and working conditions and, consequently, impacts the process of implementing programmes. This study examines the influence of the organisational context on the implementation of a psycho-educational programme and an academic levelling module at Colombian schools. Specifically, we evaluate the work design characteristics of teachers and their impact on the fidelity, effectiveness, and sustainability of the intervention. Information was collected from 102 teachers who acted as facilitators in the implementation of these interventions at a total of 72 schools in the city of Barranquilla. With a work design questionnaire, the characteristics of the task and working conditions of the teaching staff were analysed. To evaluate the implementation of the programme, indicators of fidelity, dose, frequency, and perceived effectiveness of the intervention were obtained. The results show that the autonomy and intrinsic characteristics of the task are positively related to the fidelity of the implementation. A certain influence of the working conditions of the teaching staff was also observed in the dose of the educational activities performed. Complementary to this, we describe the impact of confinement during the coronavirus pandemic on the implementation of programmes. Work design influences the process of implementing programmes in educational contexts. Both active hierarchical supervision and the motivational characteristics of teachers' work affect the sustainability of interventions, especially in crisis circumstances. To conclude, we reflect on the organisational characteristics that facilitate the sustainability of the interventions.

\footnotetext{
${ }^{1}$ Universidad de Sevilla, Sevilla, Spain. ${ }^{2}$ Universidad del Norte, Barranquilla, Colombia. ${ }^{凶}$ email: isidromj@us.es
} 


\section{Introduction}

\| / mplementation matters" (Durlak and DuPre, 2008). The impact of the programmes not only depends on an adequate scientific design but on how they are put into practice in specific community contexts. In that process, organisational factors are decisive. When the programmes are applied at the school, it is relatively common for the teachers themselves to be responsible for implementing the psycho-educational activities rather than external professionals. The integration of the programme with regulated activities tends to improve its coverage and relevance. However, it also makes it dependent on the internal dynamics of the school and its staff management policies.

In an extensive review of the elements of the institutional and community context that determine the implementation of programmes, Durlak and DuPre (2008) confirmed the importance of organisational factors. Both the characteristics of the organisation and the training and technical assistance received by the programme's operators were key for the proper development of the interventions and, consequently, for obtaining positive results. Among others, relevant factors include leadership, organisational climate, teamwork, task design and the programme's integration into the structure of the organisation. The training and motivation of those who apply the programme also has a central role in the implementation process.

The impact of organisational factors has been confirmed with the evaluation of programmes at schools. Culture and organisational climate modulate the work attitudes of teaching staff and influence the sustainability of the programmes, in such a way that the working atmosphere is associated with the fidelity of the implementation (Williams et al., 2019). Therefore, taking into account the diversity of profiles, the programmes face unique application conditions at each school. We also know that the training and technical assistance received by the teaching staff increase the fidelity of the implementation at schools (Eiraldi et al., 2014), whereas continuous supervision can facilitate the proper development of the programme (Wolfenden et al., 2014).

However, it has been comparatively rare to adopt a work design approach to examine how the position, tasks and roles of compulsory education teaching staff are structured, as well as the impact of these structures and regulations on the implementation process of programmes. The work design model assumes that the nature and content of the job affect worker satisfaction and performance, among other psychological outcomes of interest. Hence the importance of examining the degree of autonomy and feedback that tasks carried out in work contexts entail, along with other characteristics of the position (Parker et al., 2001). With this perspective, applied systematically, it could be explored how the design of positions and the organisational design determine the implementation and performance of the programmes in school contexts.

\section{Overload, supervision, and characteristics of the work in the implementation of programmes}

As we have outlined, the implementation of programmes at schools partly depends on how they are integrated into the organisational context. In the event that the applicators are the teachers themselves, the evolution of the programme depends on how it is articulated with their usual teaching obligations, as well as the training and technical support they receive or the degree of availability of the resources needed for the implementation. Among other organisational factors, the workload (Lichtenstein, 1982), the support of hierarchical superiors (Ugwu and Onyancha, 2019), and the characteristics of the work design (Rosati and Faria, 2019) may have an influence.
On the one hand, an overload of work may cause a conflict between daily activities and the demands of teaching staff to implement the programme. This often results in stress and hinders the development of the plans made, affecting the fidelity of the implementation (Lichtenstein, 1982). On the contrary, teamwork reduces the workload and improves the performance of the programme's applicators.

On the other hand, the support of the school's management can contribute to obtaining the budget, logistical support and legitimacy necessary for the proper functioning of the programme (Aksorn and Hadikusumo, 2010; Ugwu and Onyancha, 2019). Specifically, the management provides materials that facilitate the implementation with the appropriate fidelity (Chaux et al., 2017; Lochmiller et al., 2016), and modulates the necessary degree of organisational flexibility to introduce innovations (Sperandio et al., 2009).

All these dynamics are related to the size and structure of the organisation, which in turn are reflected in the characteristics of the work design. Both the organisational diversity of schools and the peculiarities of the work performed by the teaching staff in each case determine the implementation of the programme. In that respect, it is worth mentioning the importance of the size of the class groups (Correa and González, 2016), together with the degree of training and motivation of the teaching staff (Benveniste \& McEwan, 2000).

In accordance with this background information, in this research we use the work design approach to explore how overload, work supervision and the characteristics of the task determine the implementation of programmes in educational contexts. Circumstantially, the study was carried out in the context of the COVID-19 pandemic, which has forced the reorganisation of teaching activities and, especially during periods of confinement, has put the organisational abilities of schools to the test. It is an exceptional situation in which, among other changes, there has been a reduction in extracurricular activities (Zaccoletti et al., 2020). Consequently, in a complementary manner, this study examines how the implementation process was affected by the exceptional circumstances of the pandemic and how it was conditioned by the organisational factors of the schools.

\section{The implementation of two intervention modules with minors in educational contexts}

Psychosocial interventions to develop social-emotional competencies at school have been shown to be effective in improving academic performance (Corcoran et al., 2018). In addition, when a comprehensive perspective is adopted, with the involvement of the family and the community, positive results are obtained in the levels of social and emotional adjustment, behavioural adjustment, and internalising symptoms (Goldberg et al., 2019). These types of programmes are implemented during a critical developmental period that can have long-term effects and under conditions that facilitate access to the population as a whole (Maya-Jariego, 2021).

In this study, we examine the implementation process of two different programmes in school contexts: (a) a psychoeducational intervention to promote the development of socioemotional skills (the Pisotón programme); and (b) two academic levelling and reinforcement modules with minors who have difficulties completing or accessing compulsory education. This allows us to compare a programme whose activities are integrated into regulated teaching with another that consists precisely of offering an alternative to those who have been excluded from formal education or are at risk. 
Pisotón is a "psycho-affective development and emotional education programme" promoted by the University of the North (Barranquilla, Colombia). The implementation is based on fun activities, group dynamics and experiential stories to promote emotional development, self-knowledge, relationships with parents and the resolution of interpersonal conflicts. It is implemented in early childhood, with children aged under 5, normally in groups of 10 students. The programme has been applied for over 20 years with positive results both in emotional development and in the resolution of interpersonal conflicts (Manrique-Palacio et al., 2018). The teaching staff receives training and specialised technical support throughout the development of the programme.

The Flexible Methodologies programme consists of teaching an academic levelling module to reinforce basic knowledge in literacy and mathematics (in the lower school years), and all other subjects (in the upper school years). As a general rule, the participants belong to vulnerable groups, high social risk groups, culturally diverse populations and other students with problems accessing the standard education provided. It is taught in two different versions. Firstly, the Brújula classrooms focus on illiterate children aged between 9 and 14 years who have been excluded from formal schooling. Secondly, the Accelerated Learning modules are normally aimed at a heterogeneous group of children aged between 10 and 15 years who have had difficulties completing primary education or who have accumulated a significant gap with respect to the level corresponding to them based on their age (Ministry of Education of Colombia, 2010). This is normally taught in groups of 25 students.

\section{Research questions}

This study aimed to verify whether the organisational factors of schools determine the implementation process of two psychoeducational programmes: Pisotón and Flexible Methodologies. First, we evaluated the variability in the fidelity, dose and frequency of implementation based on the design of the work performed by teaching staff. We then explored the existing types of educational organisations along with the implementation process associated with each profile. In both cases, we also evaluated the differences in the perceived effectiveness of the intervention. Therefore, this study attempted to achieve the following research objectives:

1. To describe how perceived characteristics of the work environment influence the quality of implementation of two psychoeducational programmes (Q1).

2. To explore how both the perception of the work environment and the quality of implementation were affected by the emergency lockdown of educational centres due to the COVID-19 pandemic in March 2020 (Q2).

These two research questions are clearly interrelated: the pandemic offers a natural opportunity to observe how the changes that have occurred in the process of implementing programmes vary depending on the characteristics of each educational organisation.

The use of two programmes with a different organisational structure and, consequently, a different teacher work design increases the variability of the observed work environment characteristics. We start from the assumption that psychoeducational programmes do not constitute isolated entities but are embedded in a pre-existing organisational structure that conditions their operation. With this study we intend to make this process visible.

\section{Methods}

Participants. We studied the organisational factors that determine the implementation of programmes at 72 public schools in

\begin{tabular}{|c|c|c|c|c|}
\hline & Mean & (SD) & Min. & Max. \\
\hline Age & 43.75 & 9.46 & 23 & 65 \\
\hline Students enroled in class & 30.27 & 23.91 & 11 & 180 \\
\hline \multicolumn{5}{|l|}{ Experience } \\
\hline Years teaching at the school & 6.28 & 6.33 & 0.8 & 30 \\
\hline Years implementing programmes & 7.34 & 8.06 & 0.5 & 30 \\
\hline Years implementing Pisotón/Flexible & 4.04 & 3.34 & 0.2 & 16 \\
\hline & $N$ & $\%$ & & \\
\hline \multicolumn{5}{|l|}{ Gender } \\
\hline Woman & 89 & 87.3 & & \\
\hline Man & 13 & 12.7 & & \\
\hline \multicolumn{5}{|l|}{ Composition of the classes } \\
\hline $\begin{array}{l}\text { They have immigrant students from } \\
\text { Venezuela }\end{array}$ & 92 & 90.2 & & \\
\hline $\begin{array}{l}\text { With internally displaced students } \\
\text { due to political violence }\end{array}$ & 27 & 26.5 & & \\
\hline \multicolumn{5}{|l|}{ Courses taught } \\
\hline Preschool: Pisotón & 37 & 36.3 & & \\
\hline Levelling course: Brújula & 28 & 27.5 & & \\
\hline Levelling course: Accelerated learning & 37 & 36.3 & & \\
\hline
\end{tabular}

the city of Barranquilla (Colombia). To contact the schools, we used a list of teachers who, when classes were stopped due to the COVID-19 pandemic (that is, 24 March 2020), were implementing the Pisotón programme or the Flexible Methodologies programme. The contact details for the teaching staff were provided by the University of the North $(n=232)$ and the Barranquilla Ministry of Education $(n=86)$, respectively. Finally, 105 teachers voluntarily participated in the study. Between 1 and 10 teachers participated in each school as a maximum, with the mode being 1 . After discarding 3 questionnaires due to incomplete information, we were left with a sample of 102 respondents. Table 1 summarises the demographic characteristics of the participants and the classes for which they were responsible.

The average age of the respondents at the time of the survey was 43.75 , with a range between 23 and 65 years $(S D=9.46)$. The majority are women $(87.3 \%)$. The respondents teach in preschool $(n=37,36.3 \%)$ and in educational levelling courses with students who are two or three years behind their expected school year, both in the basic format of Brújula $(n=28,27.5 \%)$ and in the more advanced format of Accelerated Learning ( $n=37,36.3 \%)$. A part of them already had previous experience in the application of psycho-educational programmes $(n=46,45.1 \%)$ before implementing the Pisotón/Flexible Methodologies programme.

Each teacher is in charge of around 30 students $(S D=23.91)$. The groups are usually quite diverse in composition. It is very common for the class to have children from migrant families, from Venezuela $(n=92,90.2 \%)$, and one in four teachers also have students from families who have experienced forced internal displacement $(n=27,26.5 \%)$. Those who have students of Venezuelan origin usually have around 15 students per class with this profile $(M=15.75, \mathrm{SD}=28.05)$, whereas when they are from internally displaced families, they do not reach two students per class $(M=1.74, \mathrm{SD}=0.44)$.

It is generally an experienced teaching group. The teachers have on average a little more than 7 years of experience in the implementation of programmes and a little more than 6 years teaching at the school where they currently work. More specifically, they have applied the programme subject to our research for an average of four years. 


\section{Instruments}

Work design questionnaire (WDQ). The work design questionnaire by Morgeson and Humphrey (2006) is a self-report measure of 77 items, which are answered with a Likert scale that ranges between 1 (completely disagree) and 5 (completely agree). The questionnaire allows us to evaluate the characteristics of the task, cognitive complexity, social aspects and the characteristics of the work context. The items cover a wide diversity of dimensions, such as autonomy (e.g., "work allows me to plan how to perform my tasks"), social support (e.g., "in my work, I have the opportunity to develop great friendships") and working conditions (e.g., "the workplace is free of excessive noise"), among many others. The Spanish version has shown adequate levels of convergent and discriminant validity. The structure of 21 factors has also been confirmed in different cultural contexts, including the cases of Spain (Fernández-Ríos et al., 2017) and Colombia (Bayona et al., 2015). The entire scale showed an excellent internal consistency, with a Cronbach's Alpha coefficient equal to 0.917, above the original validation (which yielded an Alpha equal to 0.87).

Questionnaire on the implementation of programmes. To evaluate the dose, respondents were asked to indicate the duration of each activity in minutes and the number of hours the programme was applied during the last month. They also estimated the hours of monthly preparation and the hours of direct work with students. Secondly, the fidelity in the implementation of the programme was evaluated through five items, with a 5-point Likert scale, which ranged between 1 "completely disagree" and 5 "completely agree". Specifically, each participant was asked to indicate whether the programme was implemented according to the intended design, with the expected frequency, with the necessary materials, using the reference manual and with the necessary training. With the five items, an integrated indicator was built for subsequent analysis. Finally, to evaluate frequency, they indicated "how many days pass between one application of the programme and the next one with the same group". In all cases, each question was repeated in reference to the application of the programme before and during confinement.

In the second part of this instrument, they were asked about the organisational dynamics related to the implementation. Fourteen items were used to do this, with the same Likert scale mentioned above, on workload, management support and teamwork.

Perceived effectiveness of the intervention. The participating teachers carried out a subjective evaluation of the degree to which the intervention achieved the objectives, contributed to the change in the behaviour of students and allowed the programme's goals to be fulfilled. A 5-point Likert scale was also used in this case to assess the perception of the teachers.

Personal and class-group data. Information was collected regarding each respondent's teaching career and years of experience applying the programme, along with their sociodemographic data. With regard to the classes for which they were responsible, they provided data on the number of students enrolled, indicating the proportion of internally displaced students and immigrant students of Venezuelan origin.

Qualitative interviews. After applying the scales and the questionnaire, the participants were subjected to a qualitative interview in which they explained their previous responses and provided an in-depth description of the implementation of the programme in their school. A total of 70 qualitative interviews were videotaped, and subsequently viewed and analysed by 6 independent observers. Each observer carried out a thematic content analysis, with an inductive strategy of piling up the most frequent contents. The analysis was organised around the two research questions, examining how the organisational context determines the implementation of educational programmes (Q1) and exploring the changes that occurred after the pandemic (Q2). The six reports were collated and integrated by one of the researchers/authors of the study: first, he reviewed the list of topics and integrated those that were similar; and second, he reread all the transcripts and compared them to the list of topics. He then regrouped the topics into wider categories and selected the most representative examples in each case. Finally, the six observers participated in a focus group in which they contrasted the emerging categories and discussed the resulting analyses until reaching a consensual interpretation.

Procedure and data analysis. The participants were contacted by e-mail or by WhatsApp and received instructions on the instruments to be completed. The questionnaires took place by video call, with an average duration of one hour and a half. The teachers signed an informed consent form, with guarantees of confidentiality and aggregated processing of the information. After completing the set of instruments, an informal conversation was held in which the teachers exchanged their feelings about their experience in applying the programme, as well as the changes that had occurred after confinement as a result of the Covid-19 pandemic. The data were analysed with SPSS Statistics 26.

In the data analysis, we performed a first descriptive phase with comparisons of averages for related samples (before and after confinement), to show the changes experienced in the implementation of the programme. Secondly, we described the schools according to the dimensions of the work design questionnaire, with comparisons between the two programmes analysed. Thirdly, we evaluated the effect of organisational factors on the implementation of the programme through bivariate correlations, regression models and a cluster analysis. Finally, as a triangulation element, the results were compared with the qualitative information obtained in the interviews with the teaching staff.

\section{Results}

During the period of home confinement, there were very significant changes in the implementation of the programme. Hence, we start with the descriptive analysis of the data related to the second objective mentioned above (Q2), to provide a context that facilitates the interpretation of the rest of the analyses (Q1).

Changes in the implementation of the programme after confinement. All respondents indicated that the programme continued to be implemented during confinement. At the time of the interview, they declared having performed an average of $59.88 \%$ of the activities set forth in the programme $(\mathrm{SD}=20.05)$. However, they went from attending to around 28 students $(M=28.74$, $\mathrm{SD}=19.68)$ to an average of $19.84(\mathrm{SD}=15.09)$. The systematic comparison of the different dimensions of the implementation is summarised in Table 2.

The teachers estimate that the dose of the programme has reduced by approximately $40 \%$ after confinement $(M=41.94$, $\mathrm{SD}=22.67)$. Specifically, a significant reduction is observed in the time dedicated to each activity $(t=8.194, p<0.0001)$, the hours dedicated to direct work with students $(t=7.760, p<0.0001)$ and the total time dedicated to implementing the programme each month $(t=5.521, p<0.0001)$. With regard to frequency, according to the respondents, the number of days that pass between sessions also doubled $(t=-2.986, p<0.005)$.

Although over half declare having received specific training to adapt to the new situation $(n=56,54.9 \%)$, in the opinion of the 
Table 2 Comparison of the implementation of the programme before and after confinement $(n=102)$.

\begin{tabular}{|c|c|c|c|c|c|}
\hline & \multicolumn{2}{|l|}{ Before } & \multicolumn{2}{|l|}{ After } & $\boldsymbol{T}$ \\
\hline \multicolumn{6}{|l|}{ Dose } \\
\hline Preparation hours per month & 27.65 & 26.68 & 32.81 & 35.89 & -1.750 \\
\hline Hours with students per month & 71.16 & 44.35 & 39.82 & 38.17 & $7.760^{\star \star \star}$ \\
\hline Implementation hours per month & 99.53 & 61.05 & 73.28 & 60.89 & $5.521^{\star \star \star}$ \\
\hline \multicolumn{6}{|l|}{ Fidelity } \\
\hline I have applied the expected frequency & 4.35 & 0.82 & 2.86 & 1.00 & $12.130^{\star \star \star}$ \\
\hline I have the right manual & 4.43 & 0.92 & 3.58 & 1.30 & $7.004^{\star \star \star}$ \\
\hline The planned design is followed & 4.41 & 0.83 & 2.94 & 1.06 & $12.642^{\star \star \star}$ \\
\hline The necessary materials are available & 3.66 & 1.43 & 2.76 & 1.29 & $6.829^{\star \star \star}$ \\
\hline I received the necessary training & 3.99 & 1.40 & 3.22 & 1.41 & $4.618^{\star \star \star}$ \\
\hline They resolve problems & 4.15 & 1.03 & 3.80 & 1.20 & $4.255^{\star \star \star}$ \\
\hline \multicolumn{6}{|l|}{ Workload } \\
\hline Affects the frequency of sessions & 1.62 & 0.67 & 2.62 & 1.03 & $-8.458^{\star \star \star}$ \\
\hline The daily activities are a priority & 2.30 & 1.12 & 2.80 & 1.08 & $-3.788^{\star \star \star}$ \\
\hline There are numerous activities & 2.56 & 1.19 & 2.83 & 1.19 & -2214 \\
\hline I shorten the programme's activities & 2.71 & 1.28 & 3.01 & 1.19 & -2.101 \\
\hline \multicolumn{6}{|l|}{ Teamwork } \\
\hline I collaborate with other applicators & 4.08 & 1.07 & 3.40 & 1.31 & $6.158^{\star \star \star}$ \\
\hline I receive feedback & 3.91 & 1.16 & 3.54 & 1.23 & $3.513^{\star \star}$ \\
\hline We work separately & 2.03 & 1.21 & 2.35 & 1.28 & $-2.922^{\star}$ \\
\hline I give feedback to other applicators & 3.96 & 1.04 & 3.55 & 1.14 & $3.733^{\star \star \star}$ \\
\hline There is little communication & 1.98 & 1.08 & 2.27 & 1.26 & -2.381 \\
\hline
\end{tabular}

Table 3 Perceived effectiveness of the programme before and after confinement $(n=102)$.

\begin{tabular}{|c|c|c|c|c|c|}
\hline & \multicolumn{2}{|c|}{ Before } & \multicolumn{2}{|l|}{ After } & \multirow[b]{2}{*}{$\boldsymbol{T}$} \\
\hline & $M$ & SD & $\mathbf{M}$ & SD & \\
\hline Achieve the objectives & 4.41 & 0.65 & 3.47 & 1.01 & $8.883^{\star \star \star}$ \\
\hline Compliance with objectives & 4.39 & 0.6 & 3.28 & 0.92 & $10.449^{\star \star \star}$ \\
\hline $\begin{array}{l}\text { Changes in the students' } \\
\text { behaviour }\end{array}$ & 4.14 & 1.05 & 3.50 & 1.19 & $4.405^{\star \star \star}$ \\
\hline
\end{tabular}

teachers, the fidelity in implementing the programme was also affected after confinement. Together with the difficulties in adapting the planned activities to digital media, they especially highlighted the barriers in maintaining contact with parents and performing the usual accompaniment tasks with families. Generally, they believe that they have lost versatility in interaction, whereby they are forced to reduce the load of tasks assigned to the students and synthesise some activities. The remote training of socio-affective skills is also especially complex. Finally, in some cases, they documented internet connection problems that reduced the programme's coverage.

Finally, as shown by the other indicators in Table 2, the teachers perceive a decrease in the support available from school management and a slight increase in workload. As a general rule, they believe that the pressure of work activities increased during confinement $(n=88,86.2 \%)$. They also generally perceive that teamwork has reduced. In any case, the majority think that the frequency of contact with management has remained the same $(n=79,77.4 \%)$.

Perceived effectiveness of the programme. The majority of teachers think that the effectiveness of the programme has been lower as a result of the introduction of changes in the implementation, forced by the confinement ( $n=72,70.6 \%)$. Specifically, if they thought that almost two thirds of students displayed changes in their behaviour as a consequence of the programme before $(M=64.53, \mathrm{SD}=25.16)$, after confinement they estimate that the intervention achieves behavioural changes in less than half of the participants $(M=48.26, \mathrm{SD}=25)$. As observed in Table 3, the respondents believe that after confinement, they are less effective both in achieving the objectives and in obtaining a positive impact on the target population.

Characteristics of the work in schools. The teaching staff perform their work with a high degree of autonomy. They generally perform activities that involve a high level of specialisation and require the effective deployment of various skills. As is typical of professional occupations, they also perform a wide variety of tasks, with high levels of information processing. 
Table 4 Characteristics of the work at the participating schools.

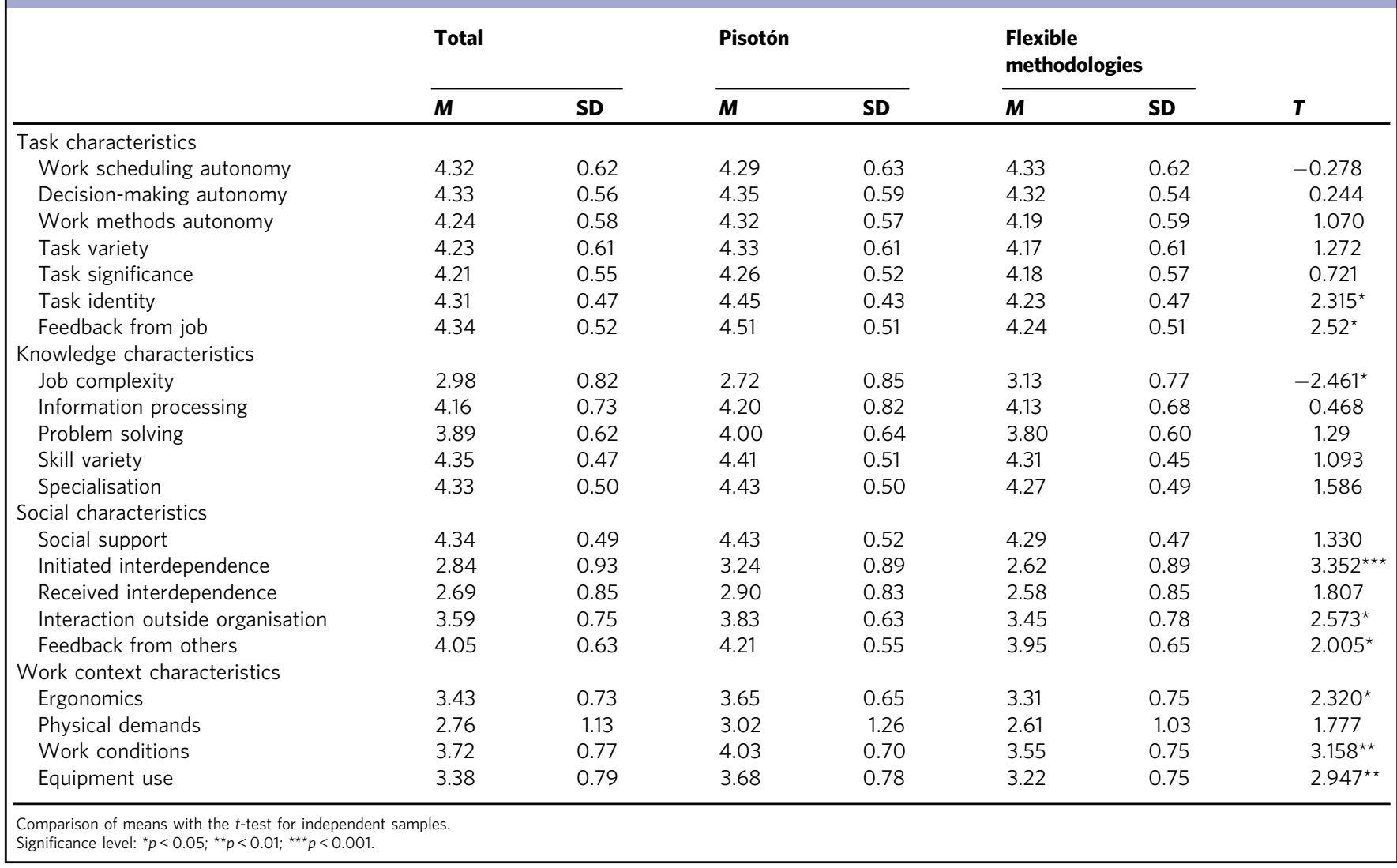

The schools in which they work are normally cohesive environments, with high levels of social support, in which they regularly exchange information with their colleagues and are exposed to the social control of their performance by third parties. As shown by the scores in Table 4, the teachers perform work of an intellectual nature with a strong social component. That is, they deal with the provision of services with a high intrinsic value that have a significant impact on the lives of other people.

Broadly speaking, the job profile is very similar at the educational units that apply the Pisotón programme and at those that apply the Flexible Methodologies programme. However, some significant differences were found, as reflected in Table 4. In particular, the applicators of the Pisotón programme perceive a greater social component in their daily activity, whereas the applicators of Flexible Methodologies assign a lower score to environmental characteristics and working conditions.

Those who implement Pisotón perceive to a greater extent that their activity in the programme influences the tasks of other external professionals, generating a certain interdependence $(t=3.352, p<0.001)$. They also report greater interaction outside the organisation $(t=2.573, p<0.05)$, as well as greater feedback from third parties $(t=2.573, p<0.05)$. This coincides with the design characteristics of both programmes, given that Pisotón is integrated into the generic preschool structure, whereas Flexible Methodologies is a specialised intervention for high-risk groups that have problems normally accessing the educational system.

With regard to the characteristics of the work context, those who apply Flexible Methodologies have a comparatively poor view of their working conditions $(t=3.158, p<0.05)$ and of the ergonomics of the working environment $(t=2.320, p<0.05)$.
They also understand that their task requires little use of complex equipment $(t=2.947, p<0.05)$.

Relationship of the organisational context with the implementation of the programme. For explanatory purposes, the bivariate correlations between the 21 factors of the work design questionnaire and the indicators of implementation and perceived effectiveness of the intervention were systematically examined both before and after confinement. The results are available in Supplementary Appendices I and II, respectively.

The characteristics of the work maintain a constant association with the fidelity of the implementation and the perceived effectiveness of the programme, especially in the dimensions related to autonomy and the intrinsic characteristics of the task (Supplementary Appendix I). However, neither the dose nor the frequency of implementation seem to be significantly affected by organisational aspects. Specifically, only the factors related to working conditions $(r=-0.286, p<0.001)$ and ergonomics $(r=-0.269, p<0.01)$ show a negative correlation with the minutes that the teachers dedicate to each activity of the programme $(r=-0.286, p<0.001)$.

The results are very different if we look at the implementation and perceived effectiveness indicators after confinement (Supplementary Appendix II): there are hardly any significant correlations with the characteristics of the work. It is only worth noting that the feedback on the tasks performed by the teaching staff is positively associated with the fidelity of the implementation ( $r=0.296, p<0.001)$, whereas the feedback provided by other members of the organisation is negatively related to the minutes dedicated to each activity of the programme $(r=-0.268$, $p<0.001)$. However, the effect size is small in all cases. 


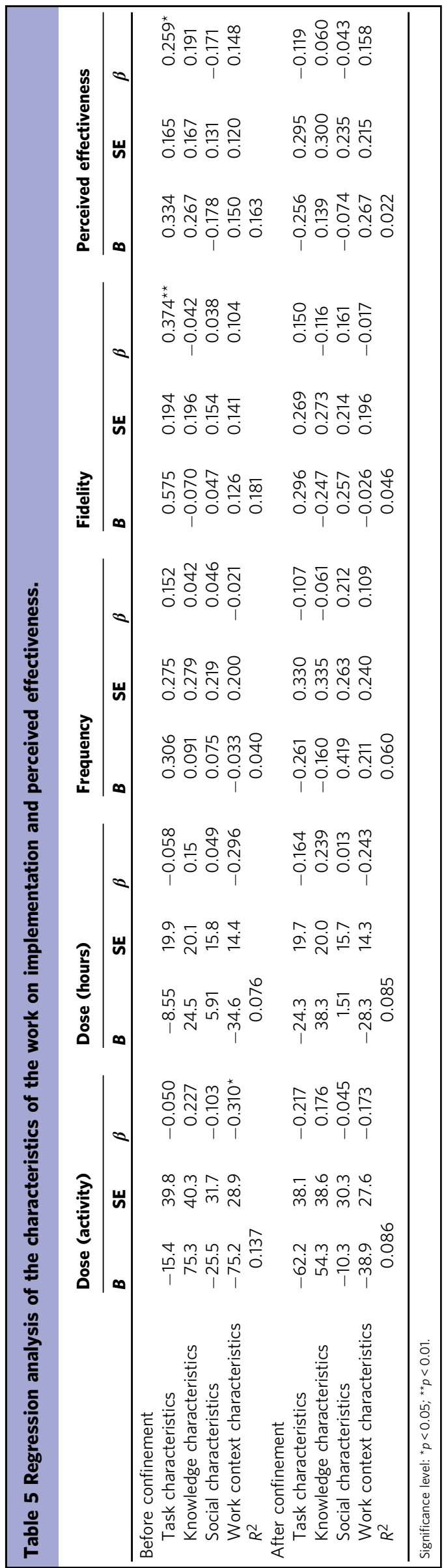

To confirm the relationship between the organisational factors and the implementation process, we performed 10 regression analyses using the four categories of the work design questionnaire as criterion variables, and five implementation indicators as dependent variables. The results are summarised in Table 5. Three regression models were statistically significant for the dependent variables of dose $(F=3.861, p<0.01)$, fidelity $(F=5.361, p<0.001)$ and perceived effectiveness $(F=4.719$, $p<0.01$ ), in the three cases before confinement. To be precise, the factor relating to "task characteristics" is a significant predictor of both the fidelity in the implementation $(B=0.210, p<0.01)$ and the perceived effectiveness of the intervention $(B=0.210$, $p<0.01)$. Moreover, the conditions of the work context showed a relationship with the minutes dedicated by teaching staff to each activity of the programme $(B=-0.310, p<0.05)$. None of the models yielded significant results after confinement.

Given that the different dimensions of the work design questionnaire tend to covariate with each other, thirdly, we turned to a cluster analysis to explore the various types of existing educational organisations. The results confirm the above observations, as summarised in Table 6 . The $K$-means cluster analysis with 10 iterations and a convergence criterion of 0.02 shows a significant classification of 2 categories. Cluster 1 ( $n=48,47.6 \%)$ has higher scores in all dimensions of the work characteristics than cluster $2(n=54,52.94 \%)$. The biggest differences are observed in the social aspects and in working conditions.

The systematic crosses with all other variables observed show a significant difference in the implementation hours of the programme $(t=-2.094, p<0.05)$ : cluster 1 dedicates an average of $90.05 \mathrm{~h}$ per month $(\mathrm{SD}=70.58)$ to applying the programme, whereas cluster 2 reaches $107.9 \mathrm{~h}(\mathrm{SD}=50.32)$. Before confinement, the first cluster has significantly more support from management $(t=3.377, p<0.001)$, it is more common for them to work as a team $(t=3.614, p<0.001)$, they implement the programme with more fidelity $(t=4.013, p<0.001)$, and they perceive a greater effectiveness of the programme's actions $(t=2.737, p<0.05)$.

In the second cluster, this is more likely to have students enrolled who are in a situation of forced displacement (ChiSquare $=4.477, p<0.05$ ) and are more represented by teachers who apply Flexible Methodologies (Chi-Square $=9.802, p<0.01$ ).

Qualitative validation of the teaching staff. The teaching staff received instructions about implementation at the start of the programme. The Flexible Methodologies module consisted of an introductory talk or a series of basic guidelines, which were later complemented with monitoring by an external advisor commissioned by the Ministry of Education. In the Pisotón programme, the implementers received an introductory training course. In both cases, the teachers coordinated through WhatsApp groups and informal meetings to exchange experiences and work as a team. This informal coordination was especially useful during the confinement period, given that it allowed them to respond to the needs of students and adapt to the new circumstances.

"We have a Brújula group on WhatsApp (...) so that at least once a week there is always a meeting between all 6 teachers (...) and we all organise how to implement the guides" [MF0602, Teacher of Flexible Methodologies, 8 years of experience in applying the programme]

The Flexible Methodologies modules have a stable educational structure, which facilitates continuity even in uncertain circumstances. For example, during confinement the teachers had to send a daily report of the activities performed and were exposed 
Table 6 Final centres of the two clusters according to the characteristics of the work $(n=102)$.

\begin{tabular}{llll} 
& $\begin{array}{l}\text { Cluster 1 } \\
(\mathbf{n = 4 8 )}\end{array}$ & $\begin{array}{l}\text { Cluster 2 } \\
(\mathbf{n = 5 4 )}\end{array}$ & Differences observed between both clusters \\
\hline Task characteristics & 4.56 & 4.04 & The second cluster dedicates more hours to applying the education module, is \\
Knowledge characteristics & 4.17 & 3.75 & less likely to work in a team, receives less support from management and applies \\
Social characteristics & 3.89 & 3.17 & the planned activities with less fidelity and perceived effectiveness. \\
Work context & 3.70 & 3.00 & \\
characteristics & & \\
\hline Convergence obtained in the second iteration, with updated means.
\end{tabular}

to a direct monitoring, with continuous supervision of their work. Moreover, the Pisotón programme is a set of activities that are applied specifically at the receiving centres. The programme's methodology is also based on reading stories to preschool children, so during confinement the participation of their parents, who in some cases could not read, was required.

Among other relevant figures during the implementation process, the participants highlighted the role of the school headmaster, the head of studies and their work colleagues. Both the headmaster and the academic coordinator set the guidelines for applying the programme and are responsible for guaranteeing the resources and spaces necessary for the implementation. Their work colleagues form a community of practice that exchanges support and tips for a proper implementation of the programme. When formal supervision is interrupted, teachers tend to resort more to informal networks with their professional colleagues.

"The fight by the school's headmaster adds real value to the programme. He fights so that teachers can be legally like other teachers in the district of Barranquilla. He does it for the love of the programme, so that the children do not miss out on their classes". [RM1210, Teacher of Flexible Methodologies, 1 year of experience in applying the programme]

"The headmaster was an accolade for me, a vote of confidence. I remember him telling me: 'I do not know the methodology; you are the expert. Manage them as they are meant to be managed. The coordinators, too... That is why we have strengthened ourselves whilst other schools in the locality have stopped running these courses" [JF0909, Teacher of Flexible Methodologies, 8 years of experience in applying the programme]

The teachers perceive that the workload is one of the factors that most determines the quantity of activities and the quality of the implementation of the programme, especially when they have students with learning difficulties or behavioural problems in the classroom. In the Flexible Methodologies modules, it is common to find people with disabilities or members of ethnic minorities who require a specific adaptation work, hence why the heterogeneity of the groups contributes to increasing the perceived workload.

"Flexible education is not the same as special education. In Barranquilla, the Flexible Methodologies modules are sometimes confused with inclusive education or special education. A child with schizophrenia or a child with Down syndrome is not the same as the learning problems of those who have been out of the education system for a long time..." [IF2212, Teacher of Flexible Methodologies, 2 years of experience in applying the programme]

"We work with ancestral traditions, with teachers who speak the Afro-Palenquera language (...) which is an aspect of identity (...)" [JF2205, Teacher of Flexible Methodologies, 11 years of experience in applying the programme]

The perception of overload increased during confinement, where many expressed difficulties in differentiating between work time and personal time. As adaptation strategies, they turned to making videos on WhatsApp, keeping in permanent contact with the families of students, recording audio with stories from the programme, printing the student guides to send them to their homes via third parties, answering phone calls to provide personalised care, and other similar activities. It also confirmed the commitment of the teachers, despite the overload that the new situation represented, especially for teachers with an active role in their homes, such as mothers.

"My work has increased; now, with implementation from home, I have to be aware of what is happening at home and also aware of my work. I am a mother and a teacher at the same time, and I feel that by putting the two things together, I am working more. [SF2901, Teacher of Pisotón,

3 years of experience in applying the programme]

One of the factors that contributed to maintaining the intensity of the implementation of the programme was the supervision by hierarchical superiors, both internal and external to the school. Despite the increased workload, teachers continued to meet the expected training rate, especially when they had to report back on a daily basis. In some cases, the activities were applied with a shorter duration in order to be able to meet the expected frequency. The monitoring and control by the hierarchical structure contributed to preserving the programme's activities in crisis circumstances.

\section{Discussion}

Both interventions analysed aim to influence the educational trajectory of minors in different ways. The Pisotón programme applies to pre-existing class groups and is integrated with other regulated activities. The Flexible Methodologies modules are formed by groups of children with special educational needs, either because they have no access to formal education or because they are at risk of abandoning their studies before completing compulsory education. The Pisotón programme develops primary strategies based on promoting socio-emotional skills. The Flexible Methodologies modules guarantee universal coverage or provide educational reinforcement through secondary or tertiary prevention actions. Despite the differences, in both cases we have verified that the organisational characteristics of the schools, and more specifically the design of the work of the teachers, determine the implementation of programmes.

From an organisational point of view, the Flexible Methodologies modules are a stable educational structure, whereas Pisotón is a programme that is applied specifically at teaching institutions. This is reflected in the supervision and control processes, which are more frequent and demanding in the first case. In turn, continuous monitoring is related to the sustainability of the 
programme, resistance to unforeseen circumstances and the development of contingency plans. During confinement, it was verified that direct supervision contributed to maintaining, to a certain degree, the frequency and dose of the intervention. In other studies conducted in educational contexts, it has also been verified that an improved supervision is related to a higher intensity in the implementation of the programme (Payne and Eckert, 2010).

However, the clearest repercussion of the organisational factors was observed in the quality of the implementation and in the impact attributed to the programme. Specifically, the task characteristics were directly associated with the fidelity of the implementation and the perceived effectiveness of the intervention. Thus, the most enriched works in terms of variety and the meaning of the tasks made it easier for the programme to be developed in accordance with what had been originally planned. This coincides with other previous evidence proving that the organisational capacities of the schools are decisive in the proper functioning of the programmes (Domitrovich et al., 2015; Thaker et al., 2008). More specifically, the formulation of tasks is one of the key organisational factors in the implementation of programmes (Durlak and DuPre, 2008).

As a consequence of the preventive confinement against COVID-19, there was a noticeable reduction in the intensity of the implementation of educational activities. This increased the perceived workload and forced the introduction of adaptations into the programme's application format. Among other changes, the involvement of parents in their children's learning increased and informal coordination mechanisms among teaching staff were strengthened. Moreover, having a smaller class group size facilitated the development of personalised strategies in the adaptation of the programme. This coincides with other cases in which changes have been introduced to guarantee the continuity of the service (Peavy et al., 2020) and carry out a remote monitoring (Annis et al., 2020).

Confinement tested the organisational capacities of the schools to improvise an emergency response and replace face-to-face activities with remote work. The high degree of autonomy, together with other motivational characteristics of the teaching work, facilitated both the transition to the new context and the introduction of adjustments into the implementation of programmes. However, the social component of the activities was significantly affected. In certain contexts, connectivity problems or power shortages, together with other infrastructure limitations, were also brought to light. Even in these circumstances, the development of skills in a selection of key employees improves the resilience of organisations when faced with critical situations (Lengnick-Hall et al., 2011).

Although the home confinement and interruption of face-toface teaching was an accidental context that occurred during the pandemic, it served to contrast our basic research objective, namely: as the characteristics of the work environment were modified, the quality of programme implementation was also affected. Furthermore, the change of the latter was different depending on the previous organisational context in each school. Thus, leadership by the principals of schools is one of the factors that improves the sustainability of interventions (Lyon et al., 2018), especially in crisis situations such as the pandemic.

Limitations and future research. In this study, we explored the impact of the characteristics of the work of teaching staff at a small number of schools, disaggregated into two programmes that in turn were applied at different educational levels. This entails great organisational variability at institutions where the programmes were applied. Along with other differences, the Flexible Methodologies modules are implemented at official schools, whereas Pisotón is applied at foundations, schools and community homes. In future research, it would be interesting to analyse representative samples that allow the diversity of organisational contexts to be systematised.

Secondly, Pisotón is a programme with its own entity, which is integrated into pre-existing schools, whereas Flexible Methodologies is an educational module for children at risk, comparable to standardised formal education. This limits the comparison possibilities. However, as we have the opportunity to verify, this also opens up an interesting future line of research on the organisational conditions that guarantee the continuity of educational services or facilitate the implementation of contingency plans in crisis circumstances.

Moreover, in this case the assessment of the impact of the interventions was limited to collecting information on the effectiveness perceived by the applicators themselves. Although this provides an approximation to the impact of the programme, it would be interesting to verify the relationship between the implementation of the interventions and the results of the participants, both in the development of their socio-emotional skills and in the educational performance indicators. Furthermore, in this case we resorted to a retrospective assessment by the teaching staff, therefore, it would be relevant to compare it with a longitudinal analysis, strictly speaking.

Practical implications. The degree of organisational structuring of the programmes is related to the continuity of the interventions. When psycho-educational actions are integrated into stable structures, the maintenance of interventions is more likely, even in crisis circumstances. The fieldwork for this study was carried out coinciding with the closure of schools during the coronavirus pandemic (COVID-19). In this context, we observed that the regulated educational activities are subject to greater pressure to guarantee their continuity than compensatory actions for groups at risk and children with special educational needs. The organisational design of educational services is not only directly related to the implementation process, but it also affects the sustainability of the interventions and their resilience to crisis or emergency situations. This is especially relevant if we take into account that those individuals and groups who are in a worse socioeducational situation are those who, in turn, are more exposed to the risk of the programmes in which they participate becoming interrupted.

Moreover, the stable structures at a school not only contribute to the development of the programmes, but they also offer teaching staff the stability they need to implement them accurately. Both the structure of the school and the design of the position collaborate with the way in which the teacher plans their activities, generates flexible and adaptive changes, and withstands pressure. In this way, the position will not cause dysfunction or a feeling of inability or personal distress (Davison et al., 2001), but will significantly help to generate or maintain a stable mental and emotional state despite the changes in the environment and in interpersonal relationships (Polo et al., 2013).

In line with previous studies, the structuring of the programme has been found to be the best predictor of the quality of the implementation (Payne and Eckert, 2010). Specifically, having standardised materials, integrating the programme into the school's education plan, developing the programme's activities during school hours and providing specialised training to teachers improve the functioning of the intervention and its sustainability throughout the school year. 
Also, to the extent that the school grants the teachers sufficient stability, as a result of appropriate working conditions and a clear orientation, they will be able to respond adaptively to the demands and requirements of the immediate environment (Acosta, 2004; and Schultz and Schultz, 2002). This ranges from consistently implementing educational programmes under normal conditions to introducing adjustments that allow for continuity during the pandemic. Decision-making both in the social and work environment largely depends on the security or stability that the context may give the person (Manrique and De Castro, 2019), as this gives them feedback on the way they are responding to the environment.

With this study, we have verified the importance of anticipating how each specific intervention programme is integrated with the set of obligations and tasks that teachers usually undertake. In fact, when the working role of teachers is expanded without increasing their organisational support, the most likely result is overload (Bartlett, 2004), which in turn negatively affects the implementation of programmes.

\section{Conclusion}

The characteristics of the work environment of schools partly condition the quality of the implementation of psychoeducational programmes. Further, the forced interruption of classroom teaching during the pandemic affected both the characteristics of the work environment and the quality of implementation. However, some elements such as continuous supervision by hierarchical superiors as well as the cohesion of the work teams contributed to maintaining a higher degree of fidelity in the implementation of the programmes.

According to our results, the fidelity of the implementation of programmes at schools partly depends on the characteristics of the teacher's task and, by extension, the work design. Moreover, despite the fact that during confinement due to COVID-19, there was a widespread reduction in the implementation indicators of programmes, the degree of supervision by hierarchical superiors was a significant predictor of the continuity of the interventions. However, the impact of school closures was generally so significant that there were no major differences in the maintenance of the implementation based on the previous organisational context.

From a practical point of view, both the integration of the programmes into the normal operations of schools and the design of teaching positions rich in autonomy, variety and meaning contribute to a better implementation of the programmes. In the future, it would be worthwhile to explore to what extent the integration of the programmes into stable organisational structures guarantees the continuity of the intervention in crisis or emergency situations, and consequently favours the shielding of educational services.

Received: 16 August 2021; Accepted: 9 February 2022; Published online: 25 February 2022

\section{References}

Acosta O (2004) Salud mental y psicología. Informes Psicol 6:57-63

Aksorn T, Hadikusumo B (2010) Investigation of critical success factors for safety program implementation in Thai construction industry. Construction and Professional Practices. Proc 10th East Asia-Pacific Conf Struct Engineer Construct 5:29-36. https://doi.org/10.1016/j.proeng.2011.07.017

Annis T, Pleasants S, Hultman G, Lindemann E, Thompson JA, Billecke S, Melton GB (2020) Rapid implementation of a COVID-19 remote patient monitoring program. J Am Med Inform Assoc 27(8):1326-1330

Bartlett L (2004) Expanding teacher work roles: a resource for retention or a recipe for overwork? J Educ Policy 19(5):565-582
Bayona JA, Caballer A, Peiró JM (2015) The work design questionnaire: Spanish version and validation. Revista de Psicología del Trabajo y de las Organizaciones 31(3):187-200

Benveniste LA, McEwan PJ(2000) Constraints to implementing educational innovations: The case of multigrade schools. Int Rev Educ 46(1):31-48

Chaux E, Barrera M, Molano A, Velásquez AM, Castellanos M, Chaparro MP, Bustamante A (2017) Classrooms in peace within violent contexts: Field evaluation of Aulas en Paz in Colombia. Prevent Sci 18(7):828-838

Corcoran RP, Cheung AC, Kim E, Xie C (2018) Effective universal school-based social and emotional learning programs for improving academic achievement: A systematic review and meta-analysis of 50 years of research. Educ Res Rev 25:56-72

Correa D, González A (2016) English in public primary schools in Colombia: Achievements and challenges brought about by national language education policies. Educ Policy Anal Archiv 24(83):1-25

Davison GC, Neale JM, Kring AM (2001) Abnormal psychology (p. 710). New York: John Wiley

Domitrovich CE, Pas ET, Bradshaw CP, Becker KD, Keperling JP, Embry DD, Ialongo $\mathrm{N}$ (2015) Individual and school organizational factors that influence implementation of the PAX good behavior game intervention. Prevent Sci 16(8):1064-1074

Durlak JA, DuPre EP (2008) Implementation matters: a review of research on the influence of implementation on program outcomes and the factors affecting implementation. Am J Commun Psychol 41(3):327-350

Eiraldi R, McCurdy B, Khanna M, Mautone J, Jawad AF, Power T, Sugai G (2014) A cluster randomized trial to evaluate external support for the implementation of positive behavioral interventions and supports by school personnel. Implement Sci 9(1):1-13

Fernández-Ríos M, Ramírez RG, Sánchez JC, Bargsted M, Polo JD, Ruiz MA (2017) Spanish-language adaptation of Morgeson and Humphrey's Work Design Questionnaire (WDQ). Span J Psychol 20(e28):1-30

Goldberg JM, Sklad M, Elfrink TR, Schreurs KM, Bohlmeijer ET, Clarke AM (2019) Effectiveness of interventions adopting a whole school approach to enhancing social and emotional development: a meta-analysis. Eur J Psychol Educ 34(4):755-782

Lengnick-Hall CA, Beck TE, Lengnick-Hall ML (2011) Developing a capacity for organizational resilience through strategic human resource management. Hum Resour Manag Rev 21(3):243-255

Lichtenstein JM (1982) A study of the implementation of the Swaziland integrated science programme. Int J Educ Dev 1(3):61-69

Lochmiller CR, Lucero A, Lester JN (2016) Challenges for a new bilingual program: implementing the International Baccalaureate Primary Years Programme in four Colombian schools. J Res Int Educ 15(2):155-174

Lyon AR, Cook CR, Brown EC, Locke J, Davis C, Ehrhart M, Aarons GA (2018) Assessing organizational implementation context in the education sector: confirmatory factor analysis of measures of implementation leadership, climate, and citizenship. Implement Sci 13(1):1-14

Manrique H, De Castro A (2019) Toma de decisiones: intuición y deliberación en la experiencia de los decisores. Innovar 29(73):149-164

Manrique-Palacio KP, Zinke L, Russo AR (2018) Pisotón: un programa de desarrollo psicoafectivo, como alternativa para construir la paz. Revista Latinoamericana de Ciencias Sociales, Niñez y Juventud 16(1):131-148

Maya-Jariego, I (2021) How to improve the implementation of child labor prevention programs. In: Community Prevention of Child Labor. Springer, Cham. pp. 51-64

Ministerio de Educación Nacional de Colombia (2010) Modelo Educativo Aceleración del Aprendizaje. Dirección de Calidad para la Educación Preescolar, Básica y Media. Subdirección de Estándares y Evaluación, Bogotá, Colombia

Morgeson FP, Humphrey SE (2006) The Work Design Questionnaire (WDQ): developing and validating a comprehensive measure for assessing job design and the nature of work. J Appl Psychol 91(6):1321

Parker SK, Wall TD, Cordery JL (2001) Future work design research and practice: Towards an elaborated model of work design. J Occup Organ Psychol $74(4): 413-440$

Payne AA, Eckert R (2010) The relative importance of provider, program, school, and community predictors of the implementation quality of school-based prevention programs. Prevent Sci 11(2):126-141

Peavy KM, Darnton J, Grekin P, Russo M, Green CJB, Merrill JO, Tsui JI (2020) Rapid implementation of service delivery changes to mitigate COVID-19 and maintain access to methadone among persons with and at high-risk for HIV in an opioid treatment program. AIDS Behav 24(9):2469-2472

Polo J, Palacio, De Castro AJ, Mebarak M, Velilla J (2013) Riesgos psicosociales: la psicología organizacional positiva como propuesta de promoción, prevención e intervención. Salud Uninorte 29(3):561-575

Rosati F, Faria LGD (2019) Business contribution to the sustainable development agenda: organizational factors related to early adoption of SDG reporting. Corp Soc Respon Environ Manag 26(3):588-597 
Schultz D, Schultz S (2002) Teorías de la personalidad. (7a. ed). Thomson Editores, México

Sperandio J, Hobson D, Douglas R, Pruitt R (2009) Does context matter? Importing US educational programs to schools overseas. Compare 39(6):707-721

Thaker S, Steckler A, Sánchez V, Khatapoush S, Rose J, Hallfors DD (2008) Program characteristics and organizational factors affecting the implementation of a school-based indicated prevention program. Health Educ Res 23(2):238-248

Ugwu CI, Onyancha OB (2019) Organizational factors and knowledge management applications to user-centred services in federal university libraries in Nigeria. J Librariansh Inf Sci 51(1):275-288

Williams NJ, Frank HE, Frederick L, Beidas RS, Mandell DS, Aarons GA, Locke J (2019) Organizational culture and climate profiles: relationships with fidelity to three evidence-based practices for autism in elementary schools. Implement Sci 14(1):1-14

Wolfenden L, Nathan N, Williams CM, Delaney T, Reilly KL, Freund M, Wiggers J (2014) A randomised controlled trial of an intervention to increase the implementation of a healthy canteen policy in Australian primary schools: study protocol. Implement Sci 9(1):1-8

Zaccoletti S, Camacho A, Correia N, Aguiar C, Mason L, Alves RA, Daniel JR (2020) Parents' perceptions of student academic motivation during the covid19 lockdown: a cross-country comparison. Front Psychol 11:592670

\section{Acknowledgements}

This study was supported by the grant provided by the Andalusian Research Plan (PAIDI in Spanish) to the Research Group "Laboratory of Personal Networks and Communities" (2019/HUM-059). The first author participated with the International Mobility Grant (Modality A) from the Internal Research Plan of the Universidad de Sevilla (I.3A VIPPITUS), through which he stayed at the Lisbon School of Economics and Management (ISEG) as a visiting professor. The fieldwork forms part of the doctoral research of Andrés Muñoz Alvis, who completed his doctoral thesis under joint supervision and with a double degree at the Universidad del Norte and the Universidad de Sevilla. Andrés Muñoz Alvis received a doctoral scholarship from the Universidad del Norte (Barranquilla, Colombia).

\section{Competing interests}

The authors declare no competing interests.

\section{Ethical approval}

The study was carried out according to the Ethical Principles of Psychologists and Code of Conduct of the American Psychological Association (APA). The research was carried out within the framework of a collaboration between the Universidad de Sevilla (Spain) and the Universidad del Norte (Colombia). The study was supervised by an academic committee responsible for a co-tutelage and double degree agreement.

\section{Informed consent}

The teachers signed an informed consent form, with guarantees of confidentiality and aggregated processing of the information.

\section{Additional information}

Supplementary information The online version contains supplementary material available at https://doi.org/10.1057/s41599-022-01081-z.

Correspondence and requests for materials should be addressed to Isidro Maya-Jariego.

Reprints and permission information is available at http://www.nature.com/reprints

Publisher's note Springer Nature remains neutral with regard to jurisdictional claims in published maps and institutional affiliations.

\begin{abstract}
cc) (i) Open Access This article is licensed under a Creative Commons Attribution 4.0 International License, which permits use, sharing, adaptation, distribution and reproduction in any medium or format, as long as you give appropriate credit to the original author(s) and the source, provide a link to the Creative Commons license, and indicate if changes were made. The images or other third party material in this article are included in the article's Creative Commons license, unless indicated otherwise in a credit line to the material. If material is not included in the article's Creative Commons license and your intended use is not permitted by statutory regulation or exceeds the permitted use, you will need to obtain permission directly from the copyright holder. To view a copy of this license, visit http://creativecommons.org/ licenses/by/4.0/.
\end{abstract}

(C) The Author(s) 2022 